\title{
Prognostic value of diffusion tensor imaging parameters for Gamma Knife radiosurgery in meningiomas
}

\author{
Herwin Speckter, MSc, ${ }^{1,3}$ Jose Bido, MD, ${ }^{1}$ Giancarlo Hernandez, MD, ${ }^{1}$ Diones Rivera Mejía, MD, ${ }^{1}$ \\ Luis Suazo, MD, ${ }^{1}$ Santiago Valenzuela, MD, ${ }^{1}$ Eddy Perez-Then, PhD, ${ }^{2}$ and Peter Stoeter, MD ${ }^{1,3}$ \\ ${ }^{1}$ Centro Gamma Knife Dominicano, and Departments of ${ }^{2}$ Science and ${ }^{3}$ Radiology, CEDIMAT, Plaza de la Salud, Santo Domingo, \\ Dominican Republic
}

OBJECTIVE Diffusion tensor imaging (DTI) parameters are able to differentiate between meningioma subtypes. The hypothesis that there is a correlation between DTI parameters and the change in tumor size after Gamma Knife radiosurgery (GKRS) was analyzed.

METHODS DTI parameters were measured using MRI before GKRS in 26 patients with meningiomas. The findings were correlated with the change in tumor size after treatment as measured at the last follow-up (range 12.5-45 months).

RESULTS Only those meningiomas that showed the highest fractional anisotropy (FA), the lowest spherical index of the tensor ellipsoid (Cs), and the lowest radial diffusivity (RD) either increased or remained stable in terms of volume, whereas all other meningiomas decreased in volume. The correlation between the DTI parameters (correlation values of -0.81 for $\mathrm{FA}, 0.75$ for $\mathrm{Cs}, 0.66$ for $\mathrm{RD}$, and 0.66 for mean diffusivity) and the rate of volume change per month was significant $(p \leq 0.001)$. Other factors, including original tumor size, prescription dose, and patient age, did not correlate significantly. CONCLUSIONS Meningiomas that show high FA values-as well as low Cs, low RD, and low mean diffusivity values-do not respond as well to GKRS in comparison with meningiomas with low FA values. This finding might be due to their higher content level of fibrous tissue. In particular, the meningioma with the highest FA value (0.444) considerably increased in volume (by $32.3 \%$ after 37 months), whereas the meningioma with the lowest FA value (0.151) showed the highest rate of reduction (3.3\% per month) in this study.

http://thejns.org/doi/abs/10.3171/2016.7.GKS161455

KEY WORDS Gamma Knife; diffusion tensor imaging; meningioma; stereotactic radiosurgery

B ENIGN meningiomas are consistently responsive to Gamma Knife radiosurgery (GKRS)., ${ }^{3,9,12,16}$ However, factors such as large tumor size, low margin dose, tumor localization outside the cranial base, and prior operation or radiation treatment are negative predictors of tumor control. ${ }^{23,24}$ Meningiomas with a higher WHO grade exhibit augmented tumor progression or recurrences, ${ }^{17}$ with 3-year progression-free survival ranging from $0 \%$ to $70 \%$ depending on the tumor grade. ${ }^{6}$ However, classifying the meningioma subtype and grading using conventional MRI, including diffusion-weighted sequences ${ }^{19}$ is difficult before radiosurgery, and clinicians still rely on the biopsy or histological results obtained from a preceding operation.

New findings suggest that diffusion tensor imaging (DTI) bypasses some of the difficulties posed by the absence of histological data. High apparent diffusion coeffi- cient values are related to the Ki-67 proliferation index and tumor cellularity. ${ }^{25}$ High fractional anisotropy (FA) values and a low spherical index of the tensor ellipsoid (Cs) correspond to the fibroblastic variety of meningiomas, whereas lower FA and a higher Cs characterize endothelial meningiomas. ${ }^{11,27}$ Because tissues with a high proliferation index may have a higher response and fiber-rich tissues such as fibroblastic meningiomas may have a lower response to radiation therapy, ${ }^{2}$ we aimed to find a correlation between DTI parameters and the change in tumor size after GKRS.

\section{Methods}

We conducted a prospective cohort study over a 5-year period (early 2011 to mid-2016). Our study was approved by the hospital's institutional review board in 2011, and patient informed consent was obtained.

ABBREVIATIONS $\mathrm{Cl}=$ longitudinal index of the tensor ellipsoid; $\mathrm{Cp}=$ planar index of the tensor ellipsoid; $\mathrm{Cs}=$ spherical index of the tensor ellipsoid; $\mathrm{DTI}=$ diffusion tensor imaging; $F A=$ fractional anisotropy; GKRS = Gamma Knife radiosurgery; $M D=$ mean diffusivity; $R D=$ radial diffusivity.

SUBMITTED June 6, 2016. ACCEPTED July 5, 2016.

INCLUDE WHEN CITING DOI: 10.3171/2016.7.GKS161455. 


\section{Patients and Meningiomas}

Twenty-six patients between 26 and 80 years of age (mean 57.1 years) with meningiomas were included and treated at our Gamma Knife center. MRI scans (including DTI) were obtained within 2 months before single-dose GKRS and as follow-up examinations after an interval of at least 12 months after treatment (range 12.5-45 months; mean 30.2 months) (Table 1).

Eighteen meningiomas $(69 \%)$ were localized at the cranial base, 1 meningioma was localized at the tentorium, and 7 meningiomas were localized at the convexity. The histological results could be retrieved for 6 of 7 patients who underwent a prior operation: 4 cases were classified as meningothelial and psammomatous, and 2 cases were fibroblastic subtypes without any atypical features. Nineteen patients reported no prior surgery or pathology. Tumor size ranged between 0.6 and $40.6 \mathrm{~cm}^{3}$ with a mean volume of $8.58 \pm 8.32 \mathrm{~cm}^{3}( \pm \mathrm{SD})$ (Table 2$)$.

\section{Gamma Knife Treatment}

We used a Leksell Gamma Knife unit (model 4C; Elekta $\mathrm{AB}$ ) to perform GKRS. The prescription dose of the $50 \%$ isodose volume varied from 11 to $18 \mathrm{~Gy}$ (mean 14.0 \pm 1.7 Gy) depending on the size and localization (Table 1). Treatment was planned using a Leksell GammaPlan workstation (version 10.1; Elekta $\mathrm{AB}$ ) to optimize coverage (mean 96.9\%) and selectivity (mean $71.5 \%$ ) and reduce the dose to sensible structures like the optic system and cochlea (Table 2).

\section{MR Imaging}

MR imaging was performed using a 3T scanner (Achieva; Philips). In addition to 3D T1-weighted and routine T2-weighted sequences obtained before and after the injection of contrast medium, the following DTI sequence was measured in the pretreatment scan using the following parameters: 32 gradient directions; $b=0$ and $800 \mathrm{sec} /$ $\mathrm{mm}^{2}$; measured voxel size of $2 \times 2 \times 2 \mathrm{~mm}$; 60 slices covering the entire head; SENSE factor 2; and a scanning time of 4.5 minutes. Follow-up studies were performed using MRI about every 12 months.

\section{Postprocessing}

The tumor volumes were outlined and measured on the 3D, T1-weighted, contrast-enhanced images on the Leksell GammaPlan workstation (Fig. 1A and B). Volume change was related to the original tumor size, and only the volume change measured at the last follow-up interval was taken for evaluation.

Based on the DTI data, the software package MRI Studio (www.mristudio.org) calculated maps of FA, mean diffusivity (MD), and radial diffusivity (RD), as well as the longitudinal $(\mathrm{Cl})$, planar $(\mathrm{Cp})$, and spherical $(\mathrm{Cs})$ indices of the tensor ellipsoid (Table 2). Using the 3D function of MRIcro software (www.cabiatl.com/mricro), a region of interest covering the tumor was created on the trace images. The corresponding values were measured after transfer to the other DTI parameter maps.

We performed partial correlation analysis and correlated the change in tumor volume before and after treat-
TABLE 1. Number of patients, patient age, tumor volume, dose, and time to last follow-up

\begin{tabular}{ll}
\hline \multicolumn{1}{c}{ Characteristic } & \multicolumn{1}{c}{ Value $^{*}$} \\
\hline No. of patients & 26 \\
\hline Age, yrs & $57.1(26-80)$ \\
\hline Tumor vol, $\mathrm{cm}^{3}$ & $8.58(0.6-40.6)$ \\
\hline Prescription dose, Gy & $14.0(11-18)$ \\
\hline Time to last follow-up, mos & $30.2(12.5-45.0)$ \\
\hline
\end{tabular}

* All values are shown as the mean (range) unless otherwise indicated.

ment to the various DTI parameters using SPSS for Windows (version 20; SPSS, Inc.). We adjusted for lesion size, margin dose, and patient age by introducing these values as control variables into the partial correlation analysis in SPSS. This adjustment was necessary because these factors might influence the change in tumor volume. The level of significance was set to $95 \%$ (Table 3). For the analysis of the treatment- and patient-related parameters before GKRS and correlations to loss of tumor volume per month, we performed a linear regression analysis using the least squares method (Table 4).

\section{Results}

GKRS reduced the initial tumor volume by a mean of $27.2 \% \pm 26.9 \%( \pm \mathrm{SD})$, as measured at the last follow-up examination, which was performed after a mean interval of 2.5 years (range 12.5-45 months). The mean tumor volume reduction was found to be $0.98 \%$ per month. After adjusting for patient age, tumor size, and time to last follow-up, we saw a significant negative correlation between the reduction in tumor volume per month and the FA values measured before GKRS (correlation -0.806; $p$ $<0.001$ ). A similar correlation was found between tumor reduction and $\mathrm{Cp}$ (correlation $-0.563 ; \mathrm{p}<0.01$ ), whereas the correlation with Cs was positive (correlation 0.748; $\mathrm{p}<$ $0.001)$. Other significant positive correlations were found between tumor reduction and RD (correlation 0.658; $\mathrm{p} \leq$ 0.001 ) and MD (correlation 0.657; $\mathrm{p} \leq 0.001$ ). The correlation between tumor reduction and $\mathrm{Cl}$ did not reach statistical significance (Table 3).

In particular, the meningioma with the highest FA value (0.444) considerably increased in volume by $32.3 \%$ after 37 months, whereas the meningioma with the lowest FA value (0.151) showed the highest reduction rate of 3.3\% per month (Fig. 1). The negative relationship between change in tumor volume and FA before GKRS can also be seen in the reduction of tumor size calculated per month and pretreatment FA (Fig. 2).

Tumor regression or progression over time was not steady. Mainly during the first 6 months, there were some increases in volume in tumors that finally regressed (pseudoprogression) and vice versa. However, these data were not included in the final evaluation, which was based on the volume change measured at the last follow-up performed at least 12 months after GKRS, as mentioned previously.

In our study, 1 (4\%) meningioma progressed after GKRS (FA 0.444), 8 (31\%) meningiomas stayed stable 


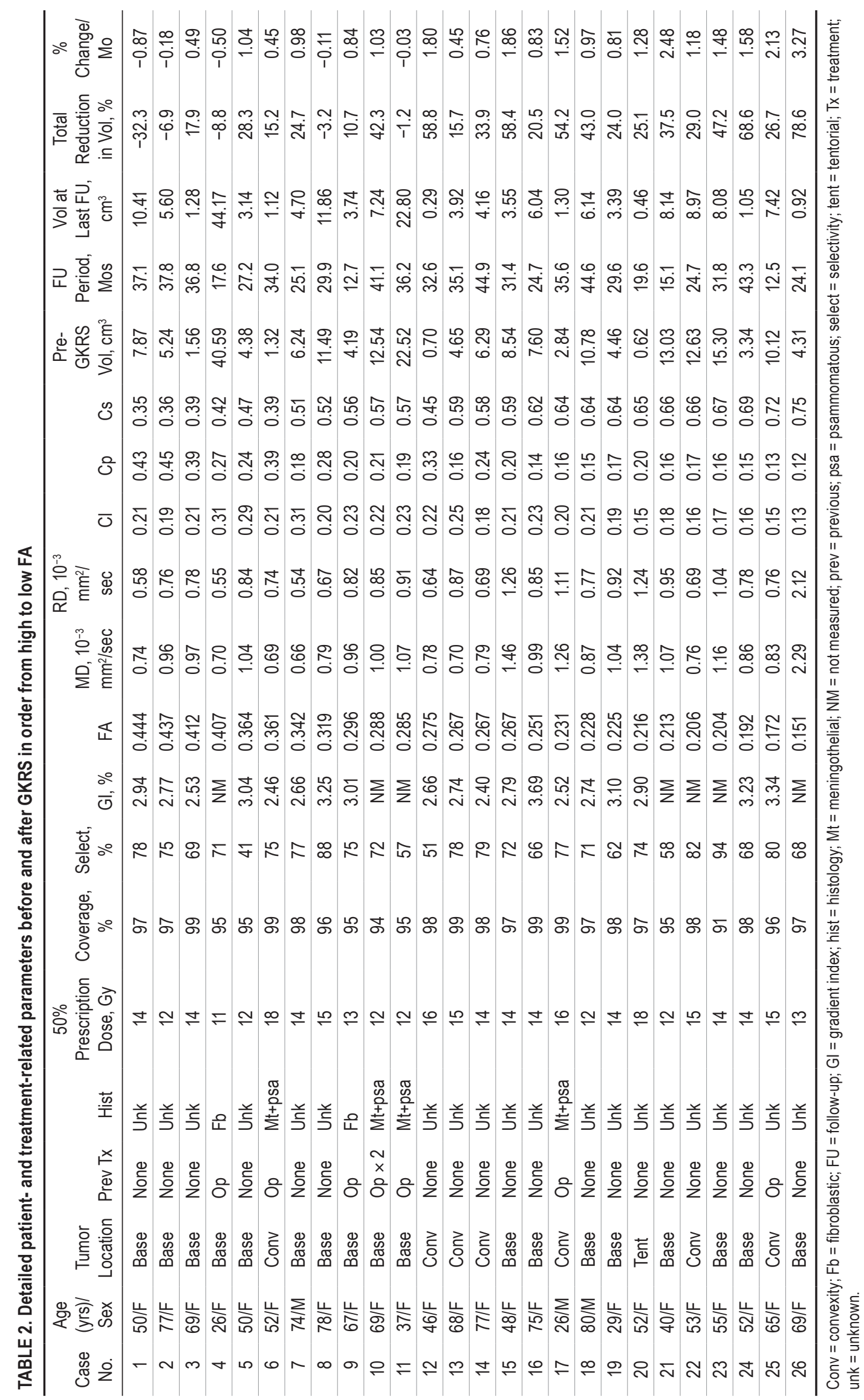



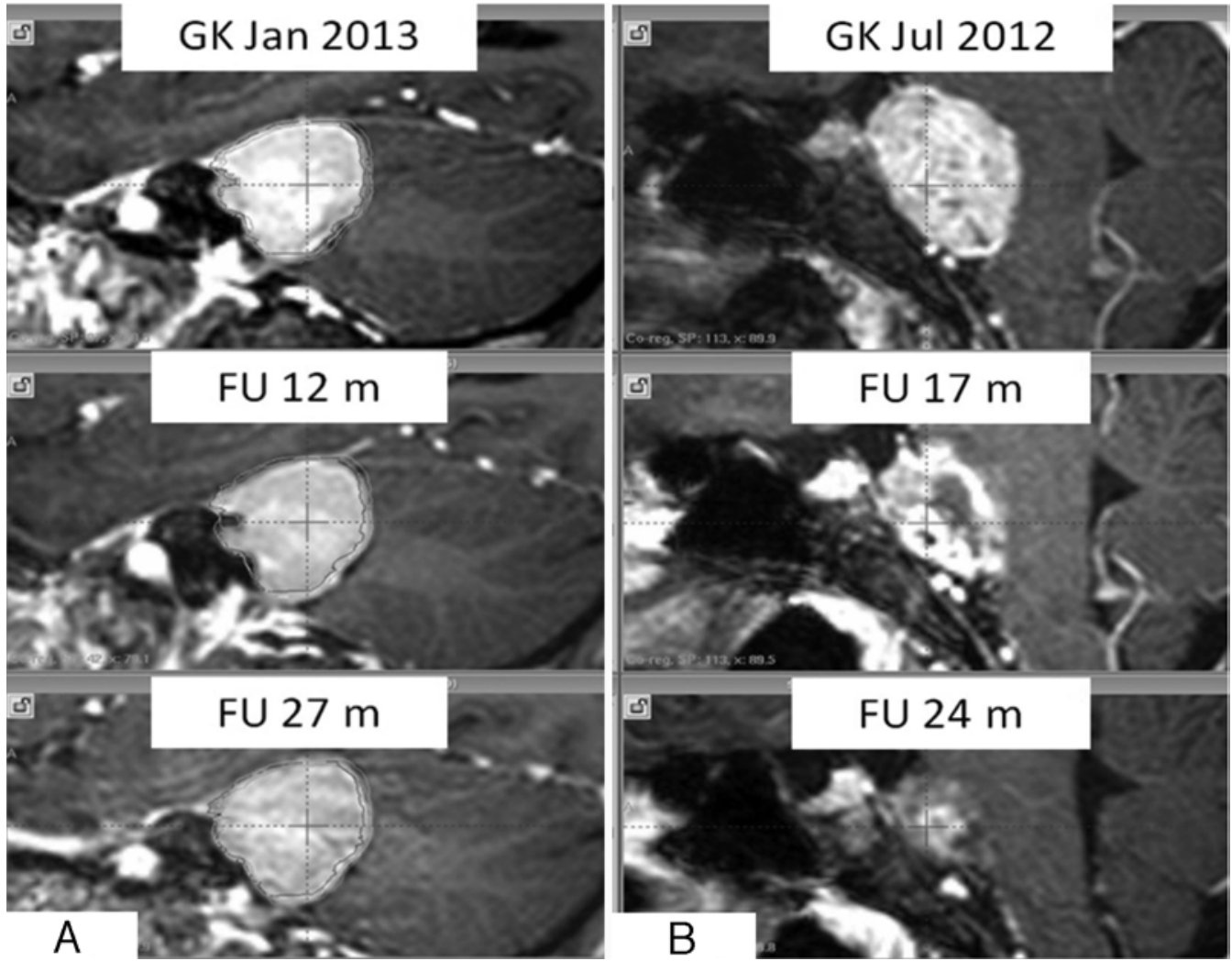

FIG. 1. A: Case 2. A 77-year-old female patient with a posterior fossa meningioma. Contrast-enhanced, T1-weighted MRI. FA value of 0.44 . Before GKRS, the volume was $5.24 \mathrm{~cm}^{3}$. No major change in volume was noted at 12 and 27 months $(\mathrm{m})$ after GKRS. B: Case 15. A 48-year-old female patient with a posterior fossa meningioma. Contrast-enhanced, T1-weighted MRI. FA value of 0.27. Before GKRS, the volume was $8.54 \mathrm{~cm}^{3}$. A 60\% reduction in volume was noted at 24 months after GKRS. FU = follow-up.

(mean FA 0.348), and 17 (65\%) meningiomas regressed (mean FA 0.241) (Table 5).

We examined other factors for their correlations with volume regression: original tumor size, marginal dose, patient age, and time to follow-up. Among these parameters, patient age and tumor size correlated negatively and radiation dose correlated positively with posttreatment reduction in tumor size, but without reaching statistical significance.

\section{Discussion}

We found that there is a relationship between the reduction in volume in meningiomas treated by GKRS and DTI parameters measured before treatment. These novel

TABLE 3. DTI parameters before GKRS and their correlations to loss of tumor volume per month

\begin{tabular}{lcrc}
\hline \multicolumn{1}{c}{ DTI Parameter } & Mean (range) & Correlation & $\mathrm{p}$ Value \\
\hline $\mathrm{FA}$ & $0.282(0.151-0.444)$ & -0.806 & $\leq 0.001$ \\
\hline $\mathrm{MD}, 10^{-3} \mathrm{~mm}^{2} / \mathrm{sec}$ & $0.994(0.663-2.290)$ & 0.657 & $\leq 0.001$ \\
\hline $\mathrm{RD}, 10^{-3} \mathrm{~mm}^{2} / \mathrm{sec}$ & $0.874(0.540-2.120)$ & 0.658 & $\leq 0.001$ \\
\hline $\mathrm{Cl}$ & $0.2077(0.13-0.31)$ & -0.309 & 0.17 \\
\hline $\mathrm{Cp}$ & $0.2258(0.12-0.45)$ & -0.563 & $\leq 0.01$ \\
\hline $\mathrm{Cs}$ & $0.5638(0.35-0.75)$ & 0.748 & $\leq 0.001$ \\
\hline
\end{tabular}

findings reached significance with a negative correlation in terms of both FA and Cs, and a positive correlation in terms of $\mathrm{Cp}, \mathrm{RD}$, and MD. By accepting the concept that DTI parameters represent some aspects of histological tumor organization, ${ }^{14,22}$ we may speculate about the different subtypes of meningiomas that were included in our cohort study and their different responses to GKRS.

GKRS effectively controls the growth of meningiomas with a control rate of $85 \%$ to $99 \%$ at follow-ups of more than 3 years. ${ }^{4,715}$ Our results are consistent with current data. In total, $89 \%(n=23)$ of meningiomas did not progress after a mean control period of 2 years. With the exception of 1 tumor that showed a volume increase of $32.3 \%$, the remaining 25 (96\%) meningiomas would not have been considered to have failed GKRS treatment in most trials. The rate of volume reduction per month $-0.98 \%$ - is consistent with previous reports. ${ }^{1,18}$ The volumetric measure-

TABLE 4. Treatment- and patient-related parameters before GKRS and their correlations to loss of tumor volume per month

\begin{tabular}{lcc}
\hline \multicolumn{1}{c}{ Parameter } & Correlation & p Value \\
\hline Initial vol & -0.315 & 0.12 \\
\hline Prescription dose & 0.122 & 0.55 \\
\hline Tumor coverage & -0.049 & 0.81 \\
\hline Patient age & -0.023 & 0.91 \\
\hline
\end{tabular}




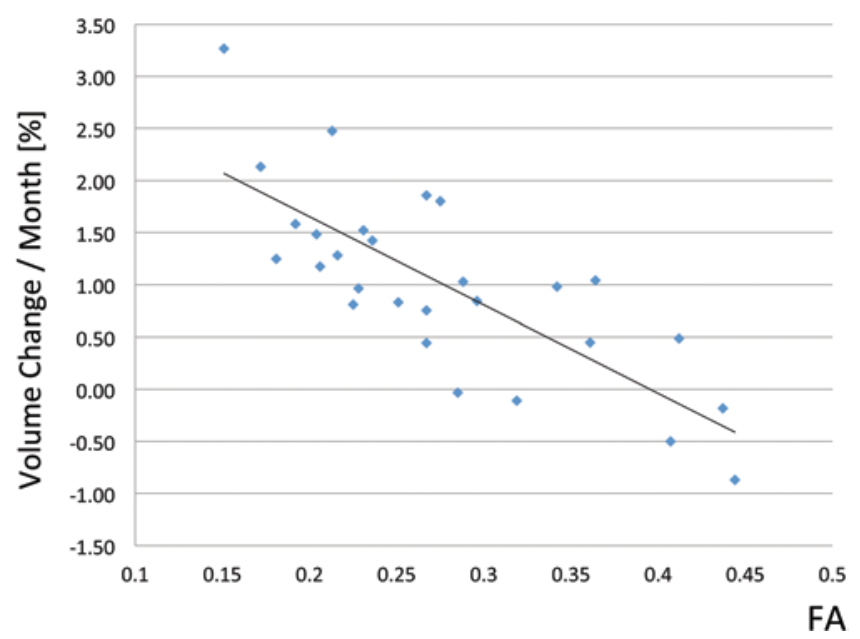

FIG. 2. Change in tumor volume per month plotted against FA before GKRS.

ments used in this study have been previously described as an effective method for estimating the efficacy of GKRS in tumor control. ${ }^{5}$

Although there is no direct proof, our hypothesis that different subtypes of meningiomas respond differently to GKRS is supported by our results. The fascicular arrangement of long spindle-shaped tumor cells and the high content levels of intra- and interfascicular fibers ${ }^{27}$ may be the reason that the high $\mathrm{FA}$ and $\mathrm{Cp}$ values and low $\mathrm{Cs}, \mathrm{RD}$, and MD levels represent the fibrous subtype rather than the endothelial subtype. As previously mentioned, the lower responsiveness of fiber-rich tissue to radiation, as it is found in this type of meningioma, is a well-known fact in radiosurgery. ${ }^{2}$

Other subtypes characterized by high FA and Cp values, as well as low Cs values, are atypical (e.g., WHO Grade II) and malignant meningiomas. ${ }^{10,28}$ A previous report ${ }^{26}$ speculated that this may be due to the lack of whorls, fascicles, cords, or nodules, which are present in typical meningiomas and may cause "water molecules to move with more directionality in atypical meningiomas because of the absence of these microscopic physical barriers." Due to the limiting factor of the lack of histological confirmation in most of our cases, we cannot rule out with certainty the inclusion of atypical subtypes in our series of 26 meningiomas. Nonetheless, the probability is low: There were no signs of brain invasion as a criterion for atypical meningioma, ${ }^{13}$ and there was no progression of growth during the first 6 months, with 2 exceptions. The 2 exceptions were single solid and well-delineated growth of the posterior fossa without signs of invasion. In addition, no atypical features were found in the 6 previously surgically treated tumors for which histological results were available.

The volume regression of meningiomas after treatment may be influenced by factors such as the original tumor volume, the prescription dose applied during GKRS, patient age, and the interval between GKRS and the control examination..$^{20,21,29}$ However, we corrected for these factors by including them as control variables in our evaluation and performing independent linear regression analyses
TABLE 5. FA values and ranges for 3 outcome groups

\begin{tabular}{ccccc}
\hline & $\begin{array}{c}\text { No. of } \\
\text { Patients } \\
(\%)\end{array}$ & $\begin{array}{c}\text { Mean } \\
\text { Reduction } \\
\text { of Vol, } \%\end{array}$ & $\begin{array}{c}\text { Mean } \\
\text { Reduction } \\
\text { of Vol/ } \\
\text { Mo, } \%\end{array}$ & $\begin{array}{c}\text { Mean FA } \\
\text { (range) }\end{array}$ \\
\hline $\begin{array}{c}\text { Tumor pro- } \\
\text { gression }\end{array}$ & $1(4)$ & -32.3 & -0.87 & $0.444(\mathrm{NA})$ \\
\hline $\begin{array}{c}\text { Unchanged } \\
\text { tumors* }\end{array}$ & $8(31)$ & 4.93 & 0.18 & $0.348(0.267-0.437)$ \\
\hline $\begin{array}{c}\text { Tumor re- } \\
\text { gression }\end{array}$ & $17(65)$ & 41.23 & 1.47 & $0.241(0.151-0.364)$ \\
\hline $\begin{array}{c}\text { NA }=\text { not applicable. } \\
*\end{array}$ & & & & \\
\hline Classified as $<20 \%$ volume increase and $<20 \%$ volume decrease.
\end{tabular}

between each factor, and the tumor volume reduction per month demonstrated negative results. The localization of a meningioma might also influence the reduction of its volume after GKRS with a less favorable response in comparison with meningiomas located outside of the cranial base. ${ }^{18}$ We saw moderate to marked regression between $15 \%$ and $59 \%$ in 1 tentorial and 7 convexity meningiomas. Thus, the influence of any factor related to localization on the statistical evaluation is regarded as small in our series.

Our study has 3 main limitations: a limited number of patients were enrolled at our relatively new Gamma Knife center, a relatively short time to the last follow-up was used, and there was a lack of histological confirmation in most cases. However, we excluded all patients with a follow-up period of less than 12 months after GKRS because the change in tumor size during this time has been reported to not be a reliable indicator of future tumor response to GKRS, and all patients who eventually exhibited tumor progression did so during the first 6 months in our study. ${ }^{8}$ Finally, biopsy before GKRS is not used routinely in most centers.

\section{Conclusions}

The significant negative correlation between FA and $\mathrm{Cp}$, the reduction in meningioma size after GKRS, and the significant positive correlations between Cs, RD, MD, and tumor shrinkage may indicate reduced radiosensitivity. However, until a biopsy-based study is conducted, the underlying histology and thus the responsible pathophysiological mechanisms will remain speculative. Our preliminary findings - that the meningioma with the lowest FA value showed the highest reduction in this study and vice versa-may lead to consequences in planning the prescription dose. Further studies are needed to clarify this relationship.

\section{Acknowledgments}

We gratefully acknowledge Ms. Cathy Lebron, Ms. Evelyn Borel, Mr. Jairo Oviedo, and Mr. Glenn Gonzalez for providing valuable contributions to this study.

\section{References}

1. Astner ST, Theodorou M, Dobrei-Ciuchendea M, Auer F, Kopp C, Molls M, et al: Tumor shrinkage assessed by volu- 
metric MRI in the long-term follow-up after stereotactic radiotherapy of meningiomas. Strahlenther Onkol 186:423429, 2010

2. Deeley TJ: Principles of Radiation Therapy. London: Butterworth, 1976

3. DiBiase SJ, Kwok Y, Yovino S, Arena C, Naqvi S, Temple $\mathrm{R}$, et al: Factors predicting local tumor control after Gamma Knife stereotactic radiosurgery for benign intracranial meningiomas. Int J Radiat Oncol Biol Phys 60:1515-1519, 2004

4. Ding D, Xu Z, McNeill IT, Yen CP, Sheehan JP: Radiosurgery for parasagittal and parafalcine meningiomas. J Neurosurg 119:871-877, 2013

5. Feigl GC, Samii M, Horstmann GA: Volumetric follow-up of meningiomas: a quantitative method to evaluate treatment outcome of Gamma Knife radiosurgery. Neurosurgery 61:281-287, 2007

6. Ferraro DJ, Funk RK, Blackett JW, Ju MR, DeWees TA, Chicoine MR, et al: A retrospective analysis of survival and prognostic factors after stereotactic radiosurgery for aggressive meningiomas. Radiat Oncol 9:38-48, 2014

7. Ganz JC, Reda WA, Abdelkarim K: Gamma Knife surgery of large meningiomas: early response to treatment. Acta Neurochir (Wien) 151:1-8, 2009

8. Harrison G, Kano H, Lunsford LD, Flickinger JC, Kondziolka D: Quantitative tumor volumetric responses after Gamma Knife radiosurgery for meningiomas. J Neurosurg 124:146-154, 2016

9. Igaki H, Maruyama K, Koga T, Murakami N, Tago M, Terahara A, et al: Stereotactic radiosurgery for skull base meningioma. Neurol Med Chir (Tokyo) 49:456-461, 2009

10. Jolapara M, Kesavadas C, Radhakrishnan VV, Thomas B, Gupta AK, Bodhey N, et al: Role of diffusion tensor imaging in differentiating subtypes of meningiomas. J Neuroradiol 37:277-283, 2010

11. Kashimura H, Inoue $\mathrm{T}$, Ogasawara $\mathrm{K}$, Arai H, Otawara $\mathrm{Y}$, Kanbara Y, et al: Prediction of meningioma consistency using fractional anisotropy value measured by magnetic resonance imaging. J Neurosurg 107:784-787, 2007

12. Linskey ME, Davis SA, Ratanatharathorn V: Relative roles of microsurgery and stereotactic radiosurgery for the treatment of patients with cranial meningiomas: a single-surgeon 4-year integrated experience with both modalities. J Neurosurg 102 Suppl:59-70, 2005

13. Louis DN, Perry A, Reifenberger G, von Deimling A, Figarella-Branger D, Cavenee WK, et al: The 2016 World Health Organization Classification of Tumors of the Central Nervous System: a summary. Acta Neuropathol 131:803-820, 2016

14. Majumdar S, Kotecha M, Triplett W, Epel B, Halpern H: A DTI study to probe tumor microstructure and its connection with hypoxia. Conf Proc IEEE Eng Med Biol Soc 2014:738-741, 2014

15. Mansouri A, Larjani S, Klironomos G, Laperriere N, Cusimano M, Gentili F, et al: Predictors of response to Gamma Knife radiosurgery for intracranial meningiomas. J Neurosurg 123:1294-1300, 2015

16. Pollock BE, Stafford SL, Link MJ, Garces YI, Foote RL: Single-fraction radiosurgery for presumed intracranial meningiomas: efficacy and complications from a 22-year experience. Int J Radiat Oncol Biol Phys 83:1414-1418, 2012

17. Pollock BE, Stafford SL, Link MJ, Garces YI, Foote RL: Stereotactic radiosurgery of World Health Organization Grade II and III intracranial meningiomas: treatment results on the basis of a 22-year experience. Cancer 118:1048-1054, 2012

18. Santacroce A, Walier M, Régis J, Liščák R, Motti E, Lindquist $\mathrm{C}$, et al: Long-term tumor control of benign intracranial meningiomas after radiosurgery in a series of 4565 patients. Neurosurgery 70:32-39, 2012
19. Sanverdi SE, Ozgen B, Oguz KK, Mut M, Dolgun A, Soylemezoglu F, et al: Is diffusion-weighted imaging useful in grading and differentiating histopathological subtypes of meningiomas? Eur J Radiol 81:2389-2395, 2012

20. Sheehan JP, Starke RM, Kano H, Barnett GH, Mathieu D, Chiang V, et al: Gamma Knife radiosurgery for posterior fossa meningiomas: a multicenter study. J Neurosurg 122:1479-1489, 2015

21. Sheehan JP, Starke RM, Kano H, Kaufmann AM, Mathieu D, Zeiler FA, et al: Gamma Knife radiosurgery for sellar and parasellar meningiomas: a multicenter study. J Neurosurg 120:1268-1277, 2014

22. Speckter H, Bido J, Hernandez G, Rivera D, Suazo L, Valenzuela S, et al: Progressive alterations of perilesional brain tissue after Gamma Knife stereotactic radiosurgery: a diffusion tensor imaging study. Innovat Neurosurg 3:35-42, 2015

23. Starke RM, Nguyen JH, Rainey J, Williams BJ, Sherman JH, Savage J, et al: Gamma Knife surgery of meningiomas located in the posterior fossa: factors predictive of outcome and remission. J Neurosurg 114:1399-1409, 2011

24. Starke RM, Williams BJ, Hiles C, Nguyen JH, Elsharkawy MY, Sheehan JP: Gamma Knife surgery for skull base meningiomas. J Neurosurg 116:588-597, 2012

25. Tang Y, Dundamadappa SK, Thangasamy S, Flood T, Moser $\mathrm{R}$, Smith T, et al: Correlation of apparent diffusion coefficient with Ki-67 proliferation index in grading meningioma. AJR Am J Roentgenol 202:1303-1308, 2014

26. Toh CH, Wei KC, Chang CN, Peng YW, Ng SH, Wong HF, et al: Assessment of angiographic vascularity of meningiomas with dynamic susceptibility contrast-enhanced perfusionweighted imaging and diffusion tensor imaging. AJNR Am J Neuroradiol 35:263-269, 2014

27. Tropine A, Dellani PD, Glaser M, Bohl J, Plöner T, Vucurevic $\mathrm{G}$, et al: Differentiation of fibroblastic meningiomas from other benign subtypes using diffusion tensor imaging. J Magn Reson Imaging 25:703-708, 2007

28. Wang S, Kim S, Zhang Y, Wang L, Lee EB, Syre P, et al: Determination of grade and subtype of meningiomas by using histogram analysis of diffusion-tensor imaging metrics. Radiology 262:584-592, 2012

29. Williams BJ, Yen CP, Starke RM, Basina B, Nguyen J, Rainey J, et al: Gamma Knife surgery for parasellar meningiomas: long-term results including complications, predictive factors, and progression-free survival. J Neurosurg 114:1571-1577, 2011

\section{Disclosures}

The authors report no conflict of interest concerning the materials or methods used in this study or the findings specified in this paper.

\section{Author Contributions}

Conception and design: Speckter, Stoeter. Acquisition of data: Speckter, Bido, Hernandez, Rivera Mejía, Suazo, Valenzuela, Stoeter. Analysis and interpretation of data: Speckter, Stoeter. Drafting the article: Speckter, Stoeter. Critically revising the article: all authors. Reviewed submitted version of manuscript: Speckter. Approved the final version of the manuscript on behalf of all authors: Speckter. Statistical analysis: Speckter, Stoeter. Administrative/technical/material support: Speckter, Perez-Then. Study supervision: Speckter.

\section{Correspondence}

Herwin Speckter, Centro Gamma Knife Dominicano and Department of Radiology, CEDIMAT, Plaza de la Salud, Santo Domingo, Dominican Republic. email: hspeckter@cedimat.net. 